\title{
Bovine Respiratory Disease Complex - A Review
}

\author{
Praveen Kumar ${ }^{1 *}$, Anup Yadav ${ }^{1}$, Lokesh ${ }^{1}$, Rajendra Yadav $^{2}$, \\ Pankaj Kumar ${ }^{3}$ and R.P. Diwakar ${ }^{4}$
}

\author{
${ }^{1}$ Department of Animal Husbandry, Govt. of Haryana, India \\ ${ }^{2}$ Vety. Medicine, RVDEC, Mahendergarh (LUVAS, Hisar) \\ ${ }^{3}$ Disease Investigation Lab., Rohtak (LUVAS, Hisar), India \\ ${ }^{4}$ Department of Veterinary Microbiology, C.V.Sc\&A.H., N.D.U.A\&T., Kumarganj, Faizabad \\ (U.P), India
}

*Corresponding author

A B S T R A C T

\section{Keywords \\ Bovine Respiratory \\ Disease Complex; \\ BRD, Bovine, \\ Respiratory \\ Article Info \\ Accepted: \\ 04 November 2018 \\ Available Online: \\ 10 December 2018}

Bovine respiratory disease (BRD) complex is a respiratory syndrome caused by various infectious agents and represents a major economic and health problem in bovine population worldwide. Stress is the probable predisposing factor for the development of BRD complex in bovines worldwide and is also a disease of economic importance to the bovine industry. One of the challenges of bovine respiratory medicine is early detection of clinical cases of BRD. This is especially important in subclinical forms of the disease, which can be easily missed and cause important economic losses. Also, the preventative approaches to the disease are not enough. In this article, basic characteristics and current diagnosis, treatment and prevention approaches of BRD were reviewed.

\section{Introduction}

Many of the diseases that have been shown to impact the respiratory tract of cattle have been grouped into an overall category known as bovine respiratory disease (BRD) complex. This includes shipping fever syndrome, mucosal disease, enzootic calf pneumonia, acute respiratory distress syndrome, hemorrhagic syndrome and atypical interstitial pneumonia (Baker, 1995; Ames, 1997; Apley, 2006). Bovine respiratory disease is a result of the complex interaction of bacterial and viral agents, environmental conditions, management factors and the animal health (Yates, 1982; Mcvey, 2009; Nickell and White, 2010). It is a major health problem of respiratory system occurring worldwide in both dairy and feedlot cattle (Edwards, 2010), responsible for high morbidity and mortality and has been reported to cause heavy economic losses in terms of drug and veterinary costs, extra labour and production losses (Van der Fels-Klerx et al., 2001; Gagea et al., 2006; Abutarbush et al., 2012). The disease is estimated to cost $\$ 800$ million- $\$ 1$ billion annually in the USA (USDA/Agriculture Research Service, 2011), 
but there is no report regarding the economic loss in India due to BRD complex. The clinical signs of BRD complex vary according to the animal status, the level of stress that animal experiences, management practices and quantum of pathogen challenge (Sanderson, 2008; Smith, 2009; Snowder, 2009).

\section{Predisposing factors}

Animal health status is characterized by the balance between protective factors (animal resistance) and risk factors (Leblanc, 2006; Taylor, 2010). This balance depends on the interaction among the susceptible host, etiologic pathogens and the environment. Stressful managemental practices (e.g. weaning, castration, transportation, commingling, etc.) promote the transmission and proliferation of commensal, but potentially pathogenic, microbes situated in the upper respiratory tract of healthy cattle (Apley, 2006; Confer, 2009; Griffin et al., 2010). Viral and bacterial agents proliferate, become pathogenic and damage the respiratory tract during the progression of subsequent respiratory disease (Griffin et al., 2010; Panciera, 2010).

\section{Etiology}

Viruses play an important role in the development of BRD complex since they predispose the animal's lung parenchyma to bacterial infection by causing direct damage to the respiratory mucosa and inhibit the animal's defense mechanism against bacteria that are commensal in the upper respiratory tract (Hogdson et al., 2005; Taylor, 2010). The major viruses involved in precipitating this disease complex are bovine herpesvirus-1 (BHV-1) leading to Infectious Bovine Rinotracheitis (Hage et al., 1998), parainfluenza virus-3 (PIV-3) (Hartel et al., 2004), bovine respiratory syncytial virus (BRSV) (Elvander, 1996) and bovine viral diarrhoea virus (BVDV) (Van Reeth and Adair, 1997). Bovine viral diarrhea virus has been recognized as a major pathogenic partner associated in the development of BRD complex (Griffin et al., 2010; Panciera, 2010). In addition, bovine respiratory coronavirus, adenovirus and influenza-A virus have also been identified as viral pathogens involved in the development of BRD complex (Gay and Barnouin, 2009). Bacterial pathogens involved in the development of BRD complex include Pasteurella multocida, Mannheimia haemolytica (formerly Pasteurella haemolytica), Histophilus somni (formerly Haemophillus somnus) and Mycoplasma bovis(Confer, 2009; Griffin et al., 2010, Grisett et al., 2015). Other bacterial pathogens associated with BRD complex include Arcanobacterium pyogenes, Bibersteinia trehalosi and other species of Pasteurella and Mycoplasma (Griffin et al., 2010).

\section{Diagnosis}

The clinical diagnosis of BRD complex is classically based on characteristic clinical signs and symptoms (Buczinski et al., 2014). These signs which are used to make a diagnosis of respiratory disease of calves are fever, cough, ocular or nasal discharge, abnormal breathing, and auscultation of abnormal lung sounds (McGuirk and Peek, 2014). Different practical tools have been developed by researchers and producers for both beef and dairy calves (Buczinski et al., 2014). Love et al., (2014) developed clinical scoring systems for BRD complex. There are some different clinical scoring systems for BRD. The first system values are coughing (induced or spontaneous coughing, 2 points), nasal discharge (any discharge, 3 points), ocular discharge (any discharge, 2 points), ear and head carriage (ear droop or head tilt, 5 points), fever ( $\geq 39.2{ }^{\circ} \mathrm{C}$ or $102.5{ }^{\circ} \mathrm{F}, 2$ points), and respiratory quality (abnormal respiration, 2 points). Calves are categorized "BRD positive" if their total score is $\geq 4$. This system 
correctly classified $95.4 \%$ of positive cases and $88.6 \%$ of controls. The second presented system categorized the predictors and assigned weights as follows: coughing (spontaneously, 2 points), mild nasal discharge (unilateral, serous or watery discharge, 3 points), moderate to severe nasal discharge (bilateral, cloudy, mucoid, mucopurulent, or copious discharge, 5 points), ocular discharge (any discharge, 1 point), ear and head carriage (ear droop or head tilt, 5 points $)$, fever $\left(\geq 39.2{ }^{\circ} \mathrm{C}, 2\right.$ points $)$, and respiratory quality (abnormal respiration, 2 points). Calves were categorized "BRD positive" if their total score is $\geq 4$. This system correctly classified $89.3 \%$ of positive cases and $92.8 \%$ of controls. The third presented system using the following predictors and scores: coughing (spontaneous only, 2 points), nasal discharge (any, 4 points), ocular discharge (any, 2 points), ear and head carriage (ear droop or head tilt, 5 points), fever $\left(\geq 39.2{ }^{\circ} \mathrm{C}, 2\right.$ points), and respiratory quality (abnormal respiration, 2 points). Calves are categorized "BRD positive" if their total score is $\geq 5$. This system correctly classified $89.4 \%$ of positive cases and $90.8 \%$ of controls. Each of the proposed systems offers few levels of clinical signs and databased weights for on-farm diagnosis of BRD in dairy calves (Love et al., 2014).

Whole blood and nasal swab samples, nasopharyngeal swab and bronchoalveolar lavage fluid can use for detection of BRD agents with PCR and ELISA techniques (Klima et al., 2014; Capik et al., 2017; Rodriguez-Castillo et al., 2017). But periodical monitoring of the infectious agents is not practical, also expensive for a lot of farm. To improve diagnostic accuracy, several authors have focused on ancillary tests using various blood biomarkers. For example, the acute-phase proteins (APP) change in concentration after infection, inflammation, surgical trauma, or stress and can either increase (positive APP) or decrease (negative
APP) as a consequence of inflammatory stimuli before the clinical signs. Haptoglobin (Hp), serum amyloid A (SAA), and fibrinogen $(\mathrm{Fb})$ are among the most commonly reported APPs. The C-reactive protein (CRP) has also been mentioned in various species (eg, human or dog) as an important APP but has received limited interest in cattle. The serum increase of APPs can occur as soon as 4 hours after the insult for SAA and CRP or later (24-48 hours) for $\mathrm{Hp}$ and $\mathrm{Fb}$ (Abdallah et al., 2016). Antigen of some virus species, such as BVDV, BHV-1, PIV-3 or BRSV can also be identified using isolation test or ELISA methods (Uttenthal et al., 1996; Autio et al., 2007). Molecular biology techniques have also been employed to identify the viruses species-specific PCR and rt-PCR methods (Autio et al., 2007). Along with these methods some new diagnostic techniques are used now a days for the detection of BRD complex such as Virus neutralization test, Immunohistochemistry, Insitu hybridization, Complementary fixation test (CFT), Agglutination test, Antigen capture ELISA and multiplex PCR (Fulton and Confer, 2012; Jamali et al., 2014).

Important haematological findings associated with BRD complex include leokocytosis, neutrophilia, increased fibrinogen concentration and acute phase proteins. The availability of a rapid test for acute phase proteins could assist in the field diagnosis of the disease and its possible differentiation from similar diseases (Radostits et al., 2007, Richeson et al., 2013). Biochemistry in BRD complex reveals lower serum phosphorous, magnesium, potassium, iron and alkaline phosphatase levels and higher bilirubin and aspartate aminotransferase levels in affected animals (Martin and Lumbsden, 1987).

\section{Control and metaphylaxis}

As the disease is responsible for high morbidity and mortality causing heavy 
economic losses to the farmers, its timely diagnosis and treatment is very essential. Various antimicrobials have been tested and used with variable efficacy for therapeutic purpose in BRD complex from time to time. Commonly used antimicrobial drugs are penicillin (Mechor et al., 1988), enrofloxacin (Hamm et al., 1999), oxytetracycline (Keita et al., 2007), ceftiofur sodium (Hibbard et al., 2002), levofloxacin (Dumka and Srivastava, 2006), florfenicol, tulathromycin (Perrett et al., 2008, Arslan et al., 2010), marbofloxacin (Grandemange et al., 2012) and clinafloxacin (Sweeney et al., 2013).

Unfortunately, routine screening of calves for respiratory disease on the farm is rarely performed (McGuirk and Peek, 2014). The vaccines available to prevent BRD continue to improve (Hilton, 2014). In addition, a nitric oxide releasing solution (NORS) has been developed and shown to have potential in the prevention of BRD (Sheridan et al., 2016). In the other hand, purchasing single-source cattle which known history of pre- and postweaning procedures can minimize pathogen exposure and enhance immunity. Using cattle-handling techniques and facilities that promote low stress will allow host immune defences to remain effective against bacterial and viral colonization. Also, controlling BRD must be managed through a comprehensive herd health immunization and management program that effectively addresses disease challenges common to the operation (Lee et al., 2005; Edward, 2010)

In conclusion, BRD complex is still an important topic and seems to will be serious problem for cattle industry in future time because of its complex nature of etiological agents, difficulties of early diagnostic and treatment situations. Improving antibiotic resistance of the pathogens is one of the negative parts of the situation; therefore treatment alternatives are getting decrease. In this frame, prevention and early diagnose of
BRD complex have more importance for future of the cattle industry worldwide.

\section{References}

Abdallah, A., Hewson, J., Francoz, D., Selim, H. and Buczinski, S. (2016). Systematic review of the diagnostic accuracy of haptoglobin, serum amyloid A, and fibrinogen versus clinical reference standards for the diagnosis of bovine respiratory disease. J. Vet. Intern. Med., 30(4): 1356-1368.

Abutarbush, S.M., Pollock, C.M., Wildman, B.K., Perrett, T. and Schunicht, O.C. (2012). Evaluation of the diagnostic and prognostic utility of ultrasonography at first diagnosis of presumptive bovine respiratory disease. Can. J. Vet. Res., 76(1): 2332.

Ames, T.R. (1997). Dairy calf pneumonia: The disease and its impact. Vet. Clin. North Am. Food Anim. Pract., 13(3): 379-91.

Apley, M. (2006). Bovine respiratory disease: Pathogenesis, clinical signs, and treatment in lightweight calves. Vet. Clin. North Am. Food Anim. Pract., 22(2): 399-411.

Arslan, H.H., Yavuz, O., Nisbet, C., Cenesiz, S. and SaripinarAksu, D. (2010).Comparative evaluation of the effects of florfenicol and tulathromycin on clinical recovery and acute phase proteins in undifferentiated natural bovine respiratory disease. Revue. Med. Vet., 161(12): 535-539.

Autio, T., Pohjanvirta, T., Holopainen, R., Rikula, U., Pentikainen, J., Hauovilainen, A., Rusanen, A., Soveri, T., Sihvonen, L. and Pelkonen, S. (2007). Etiology of respiratory disease in nonvaccinated, non- 
medicated calves in rearing herds. Vet. Microb., 119: 256-265.

Baker, J.C. (1995). The clinical manifestations of bovine viral diarrhea infection. Vet. Clin. North Am.Food Anim. Pract., 11(3): 425-45.

Buczinski, S., Forte, G., Francoz, D, and Belanger, A.M. (2014). Comparison of thoracic auscultation, clinical score, and ultrasonography as indicators of bovine respiratory disease in preweaned dairy calves. J. Vet. Intern. Med. 28(1): 234-242.

Capik, S.F., White, B.J., Lubbers, B.V., Apley, M.D. and DeDonder, K.D. (2017). Comparison of the diagnostic performance of bacterial culture of nasopharyngeal swab and bronchoalveolar lavage fluid samples obtained from calves with bovine respiratory disease. Am. J. Vet. Res., 78(3): 350-358.

Confer, A.W. (2009). Update on bacterial pathogenesis in BRD. Anim. Health Res. Rev., 10(02): 145.

Dumka, V.K. and Srivastava, A.K. (2006). Pharmacokinetics, urinary excretion and dosage regimen of levofloxacin following single intramuscular administration in cross bred calves. $J$. Vet. Sci., 7: 333-337.

Edwards, T.A. (2010). Control methods for bovine respiratory disease for feedlot cattle. Vet. Clin. North Am. Food Anim. Pract., 26(2): 273-284.

Elvander, M. (1996). Severe respiratory disease in dairy cows caused by infection with bovine respiratory syncytial virus. Vet. Rec. 138: 101105.

Fulton, R.W. and Confer, A.W. (2012). Laboratory test descriptions for bovine respiratory disease diagnosis and their strengths and weaknesses: Gold standards for diagnosis, do they exist? Can. Vet. J. 53: 754-761.
Gagea, M.I., Bateman, K.G. and van Dreumel T. (2006). Diseases and pathogens associated with mortality in Ontario beef feedlots. J. Vet. Diagn. Invest. 18: $18-28$.

Gay, E. and Barnouin, J. (2009). A nationwide epidemiological study of acute bovine respiratory disease in France. Prevent. Vet. Med.89: 265-271.

Grandemange, E., Fournel, S., Giboin, H. and Woehrle, F. (2012). Efficacy of a single injection of marbofloxacin in the treatment of bovine respiratory disease. Revue. Med. Vet.163(6): 287294.

Griffin, D., Chengappa, M.M., Kuszak, J. and McVey, D.S. (2010).Bacterial pathogens of the bovine respiratory disease complex. Vet. Clin. North Am. Food Anim. Pract., 26(2): 381-394.

Grissett, G.P., White, B.J. and Larson, R.L. (2015).Structured literature review of responses of cattle to viral and bacterial pathogens causing bovine respiratory disease complex. J. Vet. Intern. Med., 29(3): 770-780.

Hage, J.J., Schukken, Y.H., Dijkstra, T., Barkema, H.W., van Valkengoed, P.H. and Wentink, G.H., (1998). Milk production and reproduction during a subclinical bovine herpes virus 1 infection on a dairy farm. Prev. Vet. Med., 34: 97-106.

Hamm, M., Wollen, T. and Highland, R. (1999). Clinical efficacy of enrofloxacin against bovine respiratory disease comparing different treatment regimens. Bov.Pract. 33: 56-59.

Hartel, H., Nikunen, S., Neuvonen, E., Tanskanen, R., Kivela, S.L., Aho, R., Soveri, T. and Saloniemi, H. (2004). Viral and bacterial pathogens in bovine respiratory disease in Finland. Acta. Vet. Scand. 45: 193-200.

Hibbard, B., Robb, E.J., Chester Jr., S.T., 
Dame, K.J., Moseley, W.W. and Bryson, W.L. (2002). Dose determination and confirmation for ceftiofur crystalline-free acid administered in the posterior aspect of the ear for control and treatment of bovine respiratory disease. Vet. Ther.3: 22-30.

Hilton, W.M. (2014). BRD in 2014: where have we been, where are we now, and where do we want to go? Anim. Health Res. Rev., 15(2): 120-122.

Hodgson, P.D., Aich, P., Manuja, A., Hokamp, K. and Roche, F.M. (2005). Effect of stress on viral-bacterial synergy in bovine respiratory disease: Novel mechanisms to regulate inflammation. Comp. Funct. Genomics. 6(4): 244-250.

Jamali, H., Rezagholipour, M., Fallah, S., Dadrasnia, A., Chelliah, A., Velappan, R.D., Wei, K.S.C. and Ismail, S. (2014). Prevalence, characterization and antibiotic resistance of Pasteurella multocida isolated from bovine respiratory infection. Vet. J. 202: 381-383.

Keita, A., Pommier, P., Pagot, E., Couper, A and Cromie, L. (2007). A combination oxytetracycline/flunixin treatment of respiratory infections in cattle. Revue. Med. Vet., 158: 86-91.

Klima, C.L., Zaheer, R., Cook, S.R., Booker, C.W. and Hendrick, S. (2014). Pathogens of bovine respiratory disease in North American feedlots conferring multidrug resistance via integrative conjugative elements. $J$. Clin. Microbiol., 52(2): 438-448.

LeBlanc, S.J. (2006). Major advances in disease prevention in dairy cattle. $J$. Dairy Sci. 89(4): 1267.

Lee, C.R., Kim, K.Y., Kim, C.N., Park, D.U. and Roh, J.H. (2005).Investigation of concentrations and correlations of airborne microbes and environmental factors in the general hospital. J. Kor. Soc. Occup. Environ. Hyg. 15: 45-51.

Love, W.J., Lehenbauer, T.W., Kass, P.H., Van Eenennaam, A.L. and Aly, S.S. (2014). Development of a novel clinical scoring system for on-farm diagnosis of bovine respiratory disease in pre-weaned dairy calves. Peer J.2: 238.

Martin, S.W. and Lumsden, J.H. (1987). The relationship of hematology and serum chemistry parameters to treatment for respiratory disease and weight gain in Ontario feedlot calves. Can. J. Vet. Res.51: 499-505.

McGuirk, S.M. and Peek, S.F. (2014).Timely diagnosis of dairy calf respiratory disease using a standardized scoring system.Anim. Health Res. Rev.15(2): $145-147$

McVey, D.S. (2009). BRD research needs in the next 10-20 years. Anim. Health Res. Rev.10(02): 165.

Mechor G.D., Jim, G.K. and Janzen, E.D. (1988).Comparison of penicillin, oxytetracycline, and trimethoprimsulfadoxine in the treatment of acute undifferentiated bovine respiratory disease.Can. Vet. J. 29: 438-443.

Nickell, J.S. and White, B.J. (2010). Metaphylactic antimicrobial therapy for bovine respiratory disease in stocker and feedlot cattle. Vet. Clin. North Am. Food Anim. Pract.26(2): 285-301.

Panciera, R.J. (2010). Pathogenesis and pathology of bovine pneumonia. Vet. Clin. North Am. Food Anim. Pract. 26(2): 191.

Perrett, T., Abutarbush, S.M. and Wildman, B.K. (2008). A comparison of florfenicol and tulathromycin for the treatment of undifferentiated fever in feedlot calves. Vet. Ther.9: 128-140.

Radostits, O.M., Gay, C.C., Blood, D.C. and Hinchcliff, K.W. (2007). Veterinary 
Medicine: A Textbook of the Diseases of Cattle, Sheep, Pigs, Goats and Horses. $10^{\text {th }}$ ed. London, England: WB Saunders. pp: 923-937.

Richeson, J.T., Pinedo, P.J., Kegley, E.B., Powell, J.G., Gadberry, M.S., Beck, P.A. and Falkenberg, S.M. (2013). Association of hematologic variables and castration status at the time of arrival at a research facility with the risk of bovine respiratory disease in beef calves. J. Am. Vet. Med. Assoc.243(7): 1035-41.

Rodriguez-Castillo, J.L., Lopez-Valencia, G., Monge-Navarro, F.J., MedinaBasulto, G.E. and Hori-Oshima, S. (2017). Detection and economic impact related to bovine respiratory disease, shrink, and travelling distance in feedlot cattle in Northwest Mexico. Turkish J. Vet. Anim. Sci.41: 294-301.

Sanderson, M.W. (2008). Risk factors for initial respiratory disease in United States feedlots based on producercollected daily morbidity counts. Can. Vet. J. 49(4): 373.

Sheridan, M.P., Regev-Shoshani, G., Martins, J., Vimalanathan, S, and Miller, C. (2016). Nitricoxide modulates the immunological response of bovine PBMCs in an in vitroBRDc infection model. Res. Vet. Sci.109: 21-28.

Smith, R.A. (2009). North American cattle marketing and bovine respiratory disease (BRD). Anim. Health Res. Rev., 10(02): 105.
Snowder, G. (2009). Genetics, environment and bovine respiratory disease. Anim. Health Res. Rev.10(02): 117.

Sweeney, M.T., Quesnell, R., Tiwari, R., LeMay, M. and Watts, J.L. (2013).In vitro activity and rodent efficacy of clinafloxacin for bovine and swine respiratory disease. Frontiers in Microbiology.4: 1-6.

Taylor, J.D. (2010). The epidemiology of bovine respiratory disease: What is the evidence for predisposing factors? Can. Vet. J. 51(10): 1095.

USDA/Agriculture Research Service. (2011). Genetic link to cattle diseases uncovered. Science Daily.

Uttenthal, A., Jensen, N.P. and Blom, J.Y. (1996). Viral aetiology of enzootic pneumonia in Danish dairy herds: diagnostic tools and epidemiology. Vet. Rec. 139: 114-117.

Van der Fels-Klerx, H.J., Sorensen, J.T., Jalvingh, A.W. and Huirne, R.B. (2001).An economic model to calculate farm-specific losses due to bovine respiratory disease in dairy heifers.Prev. Vet. Med., 51: 75-94.

Van Reeth, K. and Adair, B. (1997). Macrophages and respiratory viruses. Pathol. Biol. 45: 184-192.

Yates, W.D.G. (1982). A review of infectious bovine rhinotracheitis, shipping fever pneumonia and viral-bacterial synergism in respiratory disease of cattle. Can. J. Comp. Med., 46: 225263.

\section{How to cite this article:}

Praveen Kumar, Anup Yadav, Lokesh, Rajendra Yadav, Pankaj Kumarand Diwakar, R.P. 2018. Bovine Respiratory Disease Complex - A Review. Int.J.Curr.Microbiol.App.Sci. 7(12): 352358. doi: https://doi.org/10.20546/ijcmas.2018.712.043 